\title{
Developing Theatre for the Young in Malaysia: Benefits and Challenges
}

\author{
Roselina Johari Md. Khir \\ University of Wollongong Malaysia KDU University College \\ e-mail: roselinakhir2626@gmail.com
}

Published online: 16 June 2020

Cite this article (APA): Khir, R. J. M. (2020). Developing Theatre for the Young in Malaysia: Benefits and Challenges. Jurai Sembah, 1(1), 1-7. https://doi.org/10.37134/juraisembah.vol1.1.1.2020

\begin{abstract}
This study investigates how young people in Malaysia enjoy theatre or find it relevant at all in the era of television, films and technology. The research was done using three approaches: A Naturalistic Inquiry methodology where the research was done at site which is in Kinabatangan, in East Malaysia with 25 young people to develop a script; a creative arts methodology was done in the studio where the script was explored and developed into a performance; the last phase of the research used a primary qualitative methodology to explore how young audiences watch theatre in which the research instruments used were questionnaires and open-ended interviews. There were 9 respondents from a Primary School and 23 respondents from a secondary School. This research that came out of the practice, enabled the researcher to investigate children's life experiences and listen to them telling their stories. The knowledge gathered is that the young in Malaysia are definitely excited about theatre which communicates to them and which has aesthetic, entertaining, imaginative and educational merits. The research connected the young in East Malaysia as participants who contributed to the script with the young in West Malaysia who performed it and young audiences who watched it.
\end{abstract}

Keywords: relevance, theatre-performance, the young in Malaysia

\section{Introduction}

As a theatre practitioner and educator, a director and a playwright, my concern is in the development of theatre for the young in Malaysia, specifically between ages of 6 to 16. A leading playwright, director and theorist in American Children's theatre, Goldberg (2006, p. 127), posed the question that serves as a guide to this research: How does theatre become increasingly relevant to the life of a growing individual? Based thereupon, the study seeks to answer two guiding questions; (1) Are our young in Malaysia engaged or inspired by a theatre performance? and, (2) How is theatre relevant to the growing individual in Malaysia?

Theatre for children in Malaysia developed only in the 1990's and over time, theatre activists and practitioners had taken different approaches, with different objectives and goals in creating theatre for children. However, now, the increasing power of the media and the distraction of television has put pressure on traditional theatre to find exciting ways of artistic expression, and it is the task of the practitioner of theatre for the young to make theatrical attempts to construct a performance that gives meaning to them.

A matter of great importance in the Theatre for the Young is the search for a subject matter for young audiences. They live in an increasingly complex world, and their real concerns deserve to be addressed in the face of technological and social challenges. This research explored different interactions of the Malaysian young with theatre which culminated with a full performance of the play People of the Forest, a rainforest musical and their responses collected. 


\section{Background and Problem Statement}

The problem with adults, whether they are the policy-makers, parents, practitioners, writers, producers, have always pretty much determined what performances are fed to the young. Schonmann (2006) says the "essence of theatre is in the actor-audience encounter and the ways in which such an encounter can add meaning to life." (p. 12). Thus, both writer and producer of a play that is going to be performed for young people should consider the artistic and aesthetic elements that are going to give the most rewarding experience to them both in the writing of the play and finally in the production of the play.

As it is, overall, literature on audience reception or audience interaction is sparse. There is a need for new discourses to explore how plays engage with and impact upon audiences (Bennet, 1997; Brown \& Novak 2007). This is a good time for theatre artists as any to invest into thinking of them as exciting and receptive audience for their theatre work.

Now more than ever, living in a period towards 2030 theatre artists must think of how to engage the young to be more aware of the extraordinary change taking place around them - culturally, politically and environmentally. I thought this is a good time for theatre artists to invest into thinking of them as exciting and receptive audience for their theatre work.

I started looking at the National Culture Policy which was formulated in 1971 (The National Department for Culture and Arts, 2019). One of the objectives of the National Culture Policy was to foster and preserve national identity through national culture. As Malaysia is a multi-racial and multi-cultural country, the government sees it fit that the process of national culture development is planned to strengthen the Malaysian way of life. This cultural planning outlined the good and noble values vital in strengthening the national identity as the Malaysian race.

I then aimed to broaden the theatrical experience in the arts by connecting two communities, perhaps more when audience is brought to the performance. I was determined to interact with the young who live as far away as possible from where I am, the city of Kuala Lumpur, to get them to tell their stories for a theatre performance for the young.

Dorothy Heathcote (1976) reminds us that drama provides situations where we can or must put ourselves in the place of another; thus, empathy for others is a possible or even likely outcome of the dramatic experience. Empathy can be an important outcome of these arts experiences. Thus, with empathy, theatre arts will be a vehicle in building understanding among diverse groups. On another note, challenges in the growth of the young particularly in Malaysia will not be complete without encountering the issues of multi-cultural, racial and ethnic diversities.

Hence, I wanted to design a performance that encourages contact with ethnic and cultural diversities which will create awareness of their being part of a community and allow the young to become more aware of themselves thus achieving the goal of the Malaysian National Cultural policy. This awareness will in turn affirm their values and will give them the tool to reach out to others. The relationship to a living culture can be developed through their creativity and that is the source of empowerment for young people. I went through the map of Malaysia to find a remote place and I found a place called Kinabatangan, a small town in the east coast of Sabah.

\section{The Research Site}

Kinabatangan is about two hours by road from Sandakan, East Malaysia. According to the Kinabatangan website Malaysiasite, ${ }^{l}$ the indigenous people who live in the Kinabatangan region are known as Orang Sungai, which literally translates to 'river people.' They live along the banks of the River Kinabatangan which is the second longest river in Malaysia, with a length of 560 kilometres. Kinabatangan has different types of forests. Unfortunately, most of these forests has been cleared and what forest remains is heavily degraded, most of it having been subjected to selective logging. The Kinabatangan Corridor of Life ${ }^{2}$ was established in cooperation with World Wild-Life Fund and massive conservation effort was carried out. This effort provides a sanctuary for a population of Saltwater Crocodiles and wildlife, like Proboscis monkeys, Bornean Orangutan, Asian elephants, Sumatran rhinoceros, the Borneo river shark and a great variety of birdlife. 
The local community, particularly the young has been included in various activities with NGOs which include Home Cultivation Scheme Program, Honorary Wildlife Warden, holding capacity building programmes to enhance and develop skills in specific aspects such as nature-guiding, environmental education programme, and Homestay Programmes. The homestay programmes in Lower Kinabatangan are community run and they also owned projects for small-scale tourism. Apart from offering village accommodation they include a range of services (e.g. boat service, guides) as well as nature and cultural activities for tourists - from jungle trekking to cultural shows. These create income-generating options for the local community that capitalize on the surrounding natural environment and local culture as resources. My objective of the study was to provide a context by which I could connect young people from two different spaces and communities together through a performance of a theatre.

\section{Methodology}

The first part of the research used a Naturalistic enquiry approach. Workshops were done in a secondary school in Kinabatangan, located in the administrative town of Kinabatangan over four six-day visits in a period of 6 months. Hence, I placed myself in the context as the primary instrument to collect data. Workshops were conducted, videotaped, notes scribbled in between and recorded the activities.

It involved 25 students from the age of 11 to 15 . The workshops took place in the school's arts studio. The objective of the early workshops with these young people was to find a folktale from their community which I could develop into a script for performance. Students were asked to take turns in sharing a story they had heard from their elders or from their community, a folklore. Although 15 volunteered to tell, some had to be helped by others, and about five managed to tell full stories. Through storytelling by each of them, I found out how much these young people knew about their folklores, and how they interpreted them which would provide insights into their feelings, perceptions and their hopes for the future. I then identified the scenes or stories that they shared that made the most impact on them.

Interviews were conducted to obtain further information from a teacher in the same school and a village elder. The interviews were semi-structured consisting of open questions. It was highly exploratory and the goal was to validate the stories told by the students.

Another 6 workshops were held in the consequent visits to get a collective agreement in the form of collaborative work for a rework of the stories shared. Students were divided into groups and given some scenes to improvise. Students engaged in informal play or improvisation. The scenes they related to very well revolved around the preservation of the rainforests and animal protection as they have had a lot of exposure in tree planting and have worked as nature guides. We played jungle scenes with animals as the protagonists in the face of extinction, incorporating their folklore. This developed into a more contemporary theme.

I came home and tried to make sense from the rich data that I had collected. The best part was when I engaged myself in a reflective, imaginative process to develop the script for performance, a creative discipline. I had to constantly reflect upon myself to make sure I succeeded in generating this new, creative material. My last workshop with the respondents were held after a script was written. They were given roles and improvised the major scenes. Extra students joined in and played impromptu local music.

From Gray (1996) as in Figure 1, I adapted the process of the creation of the script as:

i. The generation or manipulation of materials at the site, natural setting.

ii. The negotiation of the outcome where selection was done and elements of pattern or plot identified.

iii. The process of conceptualization or idiographic interpretation.

iv. The interpretations of outcomes through the uniqueness of the field of practice

v. The articulation in terms of the script for a second workshop with the urban young. 


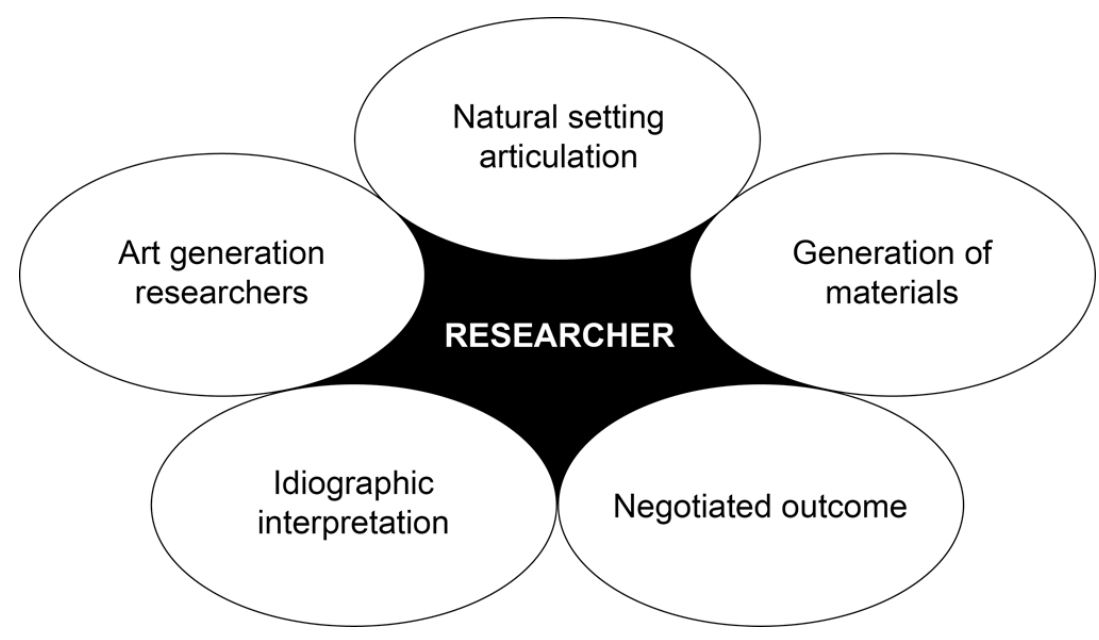

Figure 1: Process of script creation.

The second stage of the research involves creative studio work which would lead to public theatre performances to an audience of the young. Although the original aim was to continue to involve the young participants from Kinabatangan in the performance, there were inevitable obstacles, and we ended up using 17 students from a Primary School in the state of Selangor from the age of 7 to 10. Studio work was over a period of three months where the children worked with the team of director, music director and choreographer on the weekends during the school days and every day during a two-week school holiday leading to the performances.

In studio work, my team and I had to focus on the artistic process from the script to the staging, to the aesthetics, designs, music, songs and dance. The conceptual framework of this theatrical experience that we wanted to provide for the young was based on needs adapted from Schonmann (2006) which include:

i. Consideration of the theatrical elements, the artistic and the aesthetic

ii. Relating to cultural aspects

iii. Understanding psychological aspects

iv. Understanding educational aspects.

Schonmann (2006) states that "if we merge all these elements, we could create a unique art form" (p. 42). That was the objective.

I had to be constantly aware that this body of work was exploring the research questions so observation and related notation were taken, visualization, directing concept or matrix, directing journal, experimentation with materials and processes, studio rehearsals, personal narrative, reflective journal/research diary, collaboration/participation/feedback, for example workshops, and peer feedback/review.

The final stage of the research process involved putting the performance into public domain in front of young audience and adults. Ultimately this study was designed to provide a methodologically grounded understanding of how young children perceive and respond to live theatre performances. By focusing on the lived experience of theatre, the research aimed to provide evidence of the meaning of theatre to child audiences in order to enhance our understanding of what children understand, learn and remember from their live theatre experiences which can assist art practitioners and policy-makers in better understanding what theatre means to target audiences.

A qualitative method of enquiry was used in order to know whether the play and performance had engaged and inspired the young. A few procedures were carried out:

i. Interview with the 17 young cast members.

ii. Short feedback survey for parents with informal interview.

iii. Interview with 9 very young audience members between the ages of 7 to 10 immediately after the play.

iv. Interview with 23 secondary school students between the ages of 14 to 16 who watched the play three days after the play. 


\section{Discussion and Analysis}

The biggest challenge in this research was that the complexity of the methodology produced ambiguous results and the interpretation of the multi-layered data that I had. In the studio, for example, research problems and issues had to be explored. I moved between the boundaries of my imagination and theories, making meaning and tying up the concepts I had earlier identified.

The performance of the theatre event itself is a form of research worked through specific project frameworks exploring the research questions. It involved the use of different media to integrate visual, tactile, kinaesthetic, experiential data into new knowledge. The challenge then for me was making sense out of the data collected from the workshops. I had to carefully organize and manage the information I collected.

But the benefit was, it enabled me to investigate children's lived experiences and listen to them expressed it in their own terms. Indications on how the young received the play was gathered through their identifying the ways in which the theatre pieces have engaged them.

\section{The People of the Forest}

The play, a creative synthesis of the whole experience is called People of the Forest, a rain forest musical for the young. It is set in the vast rain forest of the Kinabatangan region of Sabah. The plot revolves around endangered animals of the rainforest and their narrow escape from the illegal loggers. Themes and issues of the play are the theme of instinct vs extinct; greed of man; the importance of family relationship and friendship even in animal life; preservation of life; deforestation must be stopped. The performances of the People of the Forest were over two nights and a matinee at KUASH Theatre at Pusat Seni Kreatif Kanak-Kanak Seri Bainun, Taman Tun Dr. Ismail, Kuala Lumpur, Malaysia on the 19th, 20th and 21st February 2016. It played to full houses in a theatre which could fit about $300-350$ audience. We had invited respondents on different days, a group of students from a school for the deaf, young audiences of different ages and their parents and teachers and two theatre critics. There was no charge, but we had a Collection Box at the Box-Office.

\section{Informal Interview with the Young Casts}

In order to know whether the play and performance had engaged and inspired the young, the first step taken was to interview informally the young cast themselves. Out of the 17 children who were in the play, eight of them were 11 years old, two of them were 10 years old, three of them were 9 years old, two of them was 8 years old and four of them were 7 years old. After the first day performance, they were asked regarding their understanding of the play they were acting in, on their responses on the enjoyment, aesthetic response to the play or educational value. Children were asked whether the play was fun for them as actors and whether it taught anything. These were the questions adapted from Anthony Jackson (2007).

Thirteen older kids from the age of 9-11 thought that they learned a lot of new things about endangered rainforest animals and their habits. They did not know that some of the animals like banteng or the proboscis monkey ever existed. They did not know about the threats of logging was serious and could disrupt family life. Four from the age of 11 particularly were sad for Wira who has to depart from his father at the end. They found out through the play that injured Orangutans go away and leave their families. Two of them thought that the play taught them to be responsible humans.

\section{Informal Interviews with 9 Primary School Children Audiences}

The second set of respondents were 9 primary school children from the age of 7-10 who were brought to the theatre by their tuition teacher to watch the performance. All of them had never been to a theatre before. They liked it so much, they requested to come again for the matinee performance. Although the show on Sunday was full, the producer managed to get them seated at the back of the auditorium which they did not mind. They thought the play was really fun as it taught them to appreciate animals and 'not to kill them for our advantage'. They said they could follow the plot easily and were able to relate. 


\section{Formal Interviews with 23 Secondary School Audiences}

The third set of respondents were 23 students from a Secondary School in Petaling Jaya, Selangor were invited through the English Club from the age of $14-16$. I conducted the interviews at the Reading Room at the Secondary School two days after they saw the performance. 21 of the students had been to a theatre before, and three had not. All found the play fun, definitely fun and one 15 year added that, "He felt like I could feel the actor's happiness. I found it very entertaining and fun." They all liked the acting, singing and dancing.

One 15-year-old said he liked the acting best of all, one said "the acting was brilliant!" Another 15-year-old said, "Definitely the acting. Although I liked all of it, I felt as if the acting stood out more." One 15-year-old said, "The acting was full of commitment; the singing was full of confidence; the dancing was excellent, they synchronised. They are all cute."

During the interview with the Secondary School and the Primary School respondents, the last question that was asked was whether they would have preferred to stay home and watched television or watched something on the internet, rather than watched the theatre, all of them answered a unanimous, "No, they were glad they came to see the theatre." When asked what is about the theatre that they liked, they answered, "It was watching live kids acting;" some said they "wondered if they could act like that too;" some said they "paid more attention during the show;" some answered they "liked the atmosphere, and they liked watching it with their friends."

The research explored how theatre was perceived, how it was valued and responded to by the children themselves. Jackson (2007) declares that the factors with what young people actually experience theatre are enjoyment, entertainment, education, interpretation, empathy, believability, clarity of storyline, relevance to their own lives, and vitality of the performance among others.

\section{Conclusion}

A conclusion from the above findings, is that a good theatre for the young which presents opportunities for them to identify themselves with the characters in situations they can relate to, with interesting visuals, a good story, worthwhile, will grab their attention. This was proven in the case of the 9 primary school children who requested their tuition teacher to come again the next day. None had regret their outing to the theatrical event and said they would look out for more theatre productions.

From the interviews of the young participants, the actors themselves and the young people who watched the performance, I found that they felt connected to the story and the sad plight of the animals in the rainforests in Kinabatangan. They received a lot of information about the animals' way of life, their family relationships and of their fears. They were shown of how men with their guns and machinery and careless actions can cause destruction and strike a fear in the hearts of the animals.

England (1990) has stated that plays for young people are in its own cultural group and thus should be given serious attention. This research had done exactly that. The performance was of a text developed by the young for the young. It had gone further by introducing the factor of a story developed by a community in Kinabatangan.

As a conclusion, this research has proven that good theatre is relevant to the young individuals as it is found to have given them pleasure, enjoyment, and education. It stimulates emotions and imagination. It is also found that watching the performance had led them to learn something they had not known before, and helped them to explore other parts of the worlds, specifically the realities of the animals trapped by men's encroachment into their home, the forest. By watching the play, respondents also talked about how the performance showed them new ways for them to express themselves. All in all, the study has added to the knowledge that an excellent live performance can be enjoyed by the young even in this digital era of technology, cinema and television. Most of those involved had never performed before, and those among the audience, had never even watched a theatre performance.

Most satisfying is that this research has connected the young in Kinabatangan as participants who contributed to the script with the young within the city who performed it. It was designed to connect young people from different spaces and communities together. Ultimately, a project such as this, has the potential to make this multi- cultural country more creative and innovative, if only more investments are made available in our young and the arts, strengthening connections between the industry and the different 
communities. It also indicates that an excellent live performance is one way of helping towards building a future theatre-going audience. Theatre as I found out, remains relevant to the life of a growing individual in Malaysia.

\section{References}

Bennett, S. (1997). Theatre audiences: A theory of production and reception. Routledge.

Brown, A. S., \& Novak, J. L. (2007). Assessing the intrinsic impacts of live performance. WolfBrown.

Culture and Arts. (2019). National culture policy. http://www.jkkn.gov.my/en/national-culture-policy

England, A. (1990). Theatre for the young. Macmillan Publishers Limited.

Goldberg, M. (2006). Essays on theatre for young audiences. Anchorage Press Plays.

Gray, C. (1996). Inquiry through practice: Developing appropriate research strategies. https://www.researchgate.net /publication/260512592_Inquiry_through_Practice_developing_appropriate_research_strategies\#fullTextFile Content

Heathcote, D. (1976). Drama as a learning medium. National Education publication.

Jackson, A. (2007). Theatre, education and the making of meanings. Manchester University Press.

Schonman, S. (2006). Theatre as a Medium for Children and Young People. Springer.

\section{Notes}

${ }^{1}$ Malaysia Site. (2001). Kinabatangan river. Retrieve from https://www.malaysiasite.nl/kinabatanganeng.htm

${ }^{2}$ WWF-Malaysia's Kinabatangan - Corridor of Life project aims to establish a balance between the growing demands of private land development (such as forest conversion), the local community and the need to protect its unique wildlife. Retrieved October 2019 from https://www.wwf.org.my/about_wwf/what_we_do/forests_main /kinabatangan corridor_of_life/ 